\title{
Role of lifestyle in the development of Cardiovascular diseases among the workers working in the offices.
}

1. MBBS, M.Phil, Ph.D. Associate Professor Physiology Faisalabad Medical University, Faisalabad, Pakistan.

2. MBBS

Post Graduate Resident Plastic Surgery

Allied Burn \& Reconstructive Surgery Center

Faisalabad Medical University, Faisalabad, Pakistan.

3. MBBS

House Officer Gynaecology \& Obstetrics

Allied Hospital, Faisalabad Medical University, Faisalabad, Pakistan.

Correspondence Address:

Dr. Qamar Mehboob

Department of Physiology

Faisalabad Medical University,

Faisalabad, Pakistan.

qamarmehboob89@yahoo.com

Article received on:

24/03/2020

Accepted for publication:

$27 / 05 / 2020$

\begin{abstract}
Qamar Mehboob', Waqar Arif', Sana Arif ${ }^{3}$
ABSTRACT... Objectives: The incidence of coronary heart disease in Pakistan is not well established. While the role of lifestyle risk factors and job-related conditions in the development of such diseases, still needs more clarification. Study Design: Cross-sectional study. Settings: Faisalabad Medical University, Faisalabad. Period: Jan, 2018 - Dec, 2018. Material \& Methods: 30 office workers of FMU were approached including males \& females. A semi-structured questionnaire was used. For evaluation of habitual physical activity Baecke questionnaire was used. Results: 30 office workers of FMU of age groups ranging from 20 above to 59 years $(37.333 \pm 12.103)$ were being studied. A questionnaire to evaluate lifestyle and awareness of cardiovascular diseases and risk factor profile and prevalence was administrated to the participants with 23 males and 7 females. Among all, reported smokers were 19\%. 47\% participants had never performed exercise, overall statistical analysis for physical exercise was $1.4000 \pm 0.62146, \mathrm{df}=29, \mathrm{p}<0.000,95 \% \mathrm{Cl}$. Job strain intensity was assessed according to Job Strain Index (JSI) Scale. It was reported that $53 \%$ workers had hard intensity while overall we found JSI $3.3333 \pm .75810, \mathrm{df}=29, \mathrm{p}<0.000,95 \% \mathrm{Cl}$. Conclusion: Some flexibility regarding their job, proper awareness about Cardiovascular Diseases (CVDs) and their risk factors is the need of the day.
\end{abstract}

Key words: $\quad$ Awareness, Developing Countries, Lifestyle.

Article Citation: Mehboob Q, Arif W, Arif S. Role of lifestyle in the development of Cardiovascular diseases among the workers working in the offices. Professional Med J 2020; 27(12):2669-2675. https://doi.org/10.29309/TPMJ/2020.27.12.4666

\section{INTRODUCTION}

Cardiovascular diseases are a major cause of mortality and morbidity all over the world. It is the number one killer of men worldwide. According to the latest data almost 17.5 million people were died due to cardiovascular diseases making $31 \%$ of total deaths all over the world. It is widely accepted that most of cardiovascular diseases can be prevented by decreasing risk factors like smoking, unhealthy diet, overweight, lack of exercise, having family history of any disease like hypertension, diabetes, hyperlipidaemia, poverty, lack of education and long duty hours. ${ }^{1}$ CVDs belongs to such group of diseases which are either related to the blood vessels or heart like stroke, coronary artery diseases, heart failure, peripheral artery disease, hypertension, arrhythmias, and atherosclerosis. ${ }^{2}$ Individual patient may have the accompanying elevated glucose, raised blood pressure, lack of exercise, smoking, excessive alcohol consumption, obesity, and dyslipidemia as well. Luckily, CVDs can not only be managed properly but also be prevented by strictly controlling glucose, blood pressure, smoking, lipid profile and by avoiding alcohol drinking Moreover, through lifestyle modifications for emotion, sleep, diet, and exercise, all of which are grouped as which a intervention. ${ }^{3}$ With the increase in the world population, CVDs have become one of the leading cause of death worldwide. According to the data of 2015, CVDs caused almost 17.9 million deaths in the world ${ }^{4}$ while in Chinese older than 60 , with $16 \%$ increased death rate, it became the leading cause of their death. ${ }^{5}$

There are multiple risk factors leading to CVDs such as diabetes, excessive weight gain, high blood pressure, old age and lack of physical activity more profound in office workers. Over the 
past few decades, worldwide, with excessive use of laptops, the prevalence of obesity has crossed $50 \%$ in most of the countries and is increasing in both children and adults. ${ }^{6}$ Due to high lipid profile, these patients are more prone to have high blood pressure, myocardial infarction (MI), stroke, and develop insulin resistance, which are all the leading causes for CVDs. ${ }^{7}$ Furthermore, morbidity and mortality of these diseases have increased in obese patients, especially in those with abdominal obesity. ${ }^{8}$

So, we planned to conduct a study to summarize the new findings about the multiple benefits of exercise on CVDs and role of lifestyle affecting these diseases among the workers working in the offices. We paid attention to the prevalence and risk factors of CVD and mechanisms and recommendations of physical activity. To prevent CVDs, American Heart Association recommended the general exercise of moderate intensity of 30 minutes, 5 times per week. ${ }^{9}$ Even the slightest exercise is better than doing nothing or continuous sitting for several hours such as for office workers. Furthermore, due to the different physique of every individual, a fix exercise training schedule cannot give the exact benefit to everyone. This study reviewed the exercise advantages for human body especially in CVDs through the most advance mechanism studies.

\section{MATERIAL \& METHODS}

30 office workers of FMU which comprises both males and females of different age groups ranging from 20 above to 59 years $(37.333 \pm 12.103)$ are being studied. A questionnaire to evaluate lifestyle and awareness of CVDs and risk factor profile and prevalence was administrated to the participants with 23 males and 7 females. Proper written consent was taken and confidentiality was ensured. The participants were also asked questions regarding awareness of cardiovascular diseases and lifestyle included awareness for heart attack and effect of various risk factors such as diabetes and hypertension on the genesis of cardiovascular disease. Lifestyle assessment included determination of physical activities, smoking and food choices. The physical activities were evaluated by using Habitual physical activity
(HPA) Baecke questionnaire ${ }^{10}$, in terms of formal games, exercises, jogging and in terms of daily activities such as climbing stairs at home or work. It includes 16 questions comprising three HPA scores from the past 12 months: 1) occupational physical activities score (8 questions); 2) physical exercises in leisure (PEL) score (4 questions); 3) leisure and locomotion physical activities (LLA) score (4 questions). The intensity of mental stress was assessed according to job strain index (JSI) ${ }^{11}$, which was published by Moore et al, to elaborate the guidelines for assigning a rating criteria to minimize the job strain. All the clinical assessment was done according to the lab investigation reports.

It was a cross-sectional study conducted at Faisalabad Medical University, Faisalabad, for a period of Jan 2018 - Dec, 2018.

\section{Inclusion Criteria}

- Only those individuals working in office, sitting for at least 6 hours.

- Male \& female.

- Age between 20 to 60yrs.

\section{Exclusion Criteria}

- All those workers working in the office with outdoor activities.

- History of any major illness other than CVDs.

\section{Objectives}

- To determine the prevalence of risk factors for cardiovascular diseases among the office workers.

- To assess the relationships of various risk factors with the diagnosis of cardiovascular diseases among office workers.

\section{RESULTS}

Total 30 office workers were approached. Of these respondents 23 were males and 7 were females of different age ranging from 20 above to 59 years (37.333 \pm 12.103$)$ (Table-I). Among all, reported smokers were $19 \%$. Most of the participants $(47 \%)$ had never performed exercise (Figure-1). For Baecke's $\mathrm{HPA}^{10}$ questionnaire formulas to calculate scores were as 0.76 for modalities of mild energy exertion, or 1.26 for modalities of 
moderate energy exertion, or 1.76 for modalities of strenuous energy exertion, $1.4000 \pm 0.62146$, df $=29, p<0.000,95 \% \mathrm{Cl}$. Rating criterion for $\mathrm{JSI}^{11}$ was according to Borg Scale: light $<=2$, somewhat hard $=3$, hard $=4-5$, very hard $=6-7$, near maximum $>7,3.3333 \pm 0.75810, d f=29, p$ $<0.000,95 \% \mathrm{Cl}$.

\section{Statistical Analysis}

The results were statistically analyzed by using IBM SPSS Version 20.00 All variables were expressed as mean \pm SD. The student's $t$ test was applied where needed. $P$ value $<0.05$ was considered statistically significant. Scores for Baecke's habitual physical activity questionnaire were calculated in accordance with Likert's scale $^{10}$ responses.

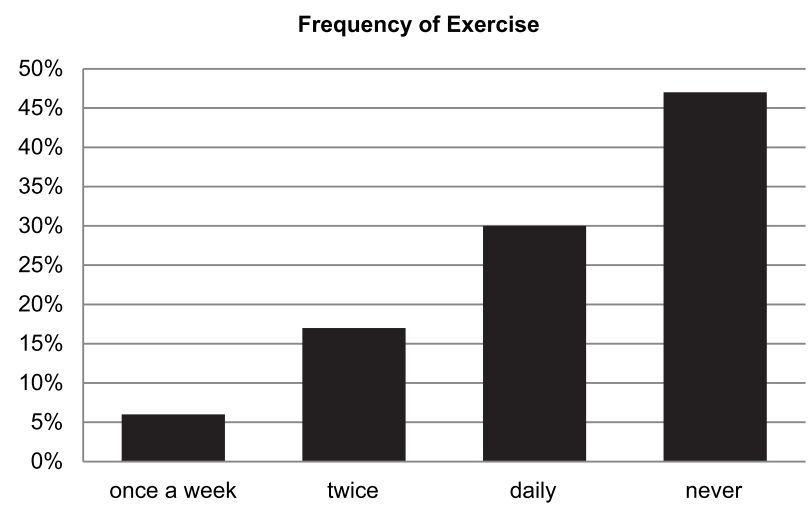

Figure-1. Graphical presentation of frequency of exercise.

\begin{tabular}{|c|c|c|c|c|c|}
\hline Salary & $<20,000$ & $20,000-50,000$ & $>50,000$ & & \\
\hline & $6(20 \%)$ & 20 (66\%) & $4(14 \%)$ & & \\
\hline \multirow[t]{2}{*}{ Smoking } & Smokers & Non-smokers & & & \\
\hline & $6(19.7 \%)$ & $24(80.3 \%)$ & & & \\
\hline \multirow[t]{2}{*}{ Type of food intake } & Vegetables & meat & $\operatorname{mix}$ & & \\
\hline & $1(1.6 \%)$ & $5(17 \%)$ & $24(81.4 \%)$ & & \\
\hline \multirow[t]{2}{*}{ Physical activities } & Light intensity & $\begin{array}{l}\text { Moderate } \\
\text { intensity }\end{array}$ & $\begin{array}{l}\text { Vigorous } \\
\text { intensity }\end{array}$ & & \\
\hline & $20(66 \%)$ & $8(26 \%)$ & $2(8 \%)$ & & \\
\hline \multirow[t]{2}{*}{$\begin{array}{l}\text { Duration of physical exercise } \\
\text { (Hours/week) }\end{array}$} & Less than 1 & $1-2$ & $2-3$ & $3-4$ & More than 4 \\
\hline & $12(40 \%)$ & $11(38 \%)$ & $6(20 \%)$ & $1(2 \%)$ & \\
\hline \multirow[t]{2}{*}{ (Months/yr) } & Less than 1 & $1-3$ & $4-6$ & 7-9 & More than 9 \\
\hline & $1(2 \%)$ & $2(7 \%)$ & $4(13 \%)$ & $9(31 \%)$ & $14(47 \%)$ \\
\hline \multirow[t]{2}{*}{ Exercise frequency } & Once a week & twice & daily & never & \\
\hline & $2(6 \%)$ & $5(17 \%)$ & $9(30 \%)$ & $14(47 \%)$ & \\
\hline \multirow[t]{2}{*}{ Duration of job } & 4-8 hrs & $10-12 \mathrm{hrs}$ & & & \\
\hline & $24(80 \%)$ & $6(20 \%)$ & & & \\
\hline \multirow[t]{2}{*}{ Intensity of Job Strain Index } & Light & Somewhat hard & hard & Very hard & Near maximum \\
\hline & $1(2 \%)$ & $1(2 \%)$ & $16(55 \%)$ & $11(39 \%)$ & $1(2 \%)$ \\
\hline \multirow[t]{2}{*}{ Education } & Matric & F.A & B.A & & \\
\hline & $13(43 \%)$ & $9(30 \%)$ & $8(27 \%)$ & & \\
\hline \multirow[t]{2}{*}{ Family history } & hypertension & diabetes & angina & none & All \\
\hline & $12(40 \%)$ & $7(24 \%)$ & $4(13 \%)$ & $6(20 \%)$ & $1(3 \%)$ \\
\hline \multirow[t]{2}{*}{ Age in yrs } & Male & female & & & \\
\hline & $37.13 \pm 19.97$ & $31.85 \pm 7.15$ & & & \\
\hline \multicolumn{6}{|c|}{ Table-I. Sample characteristics $(n=30)$} \\
\hline
\end{tabular}




\begin{tabular}{|l|c|c|c|c|c|}
\hline \multicolumn{5}{|c|}{} & \multicolumn{5}{c|}{ Descriptive Statistics } \\
\hline Age & N & Minimum & Maximum & Mean & Std. Deviation \\
\hline Valid N (listwise) & 30 & 20.00 & 59.00 & 37.3333 & 12.10396 \\
\hline \multicolumn{2}{|c|}{} & & & & \\
\hline & & \multicolumn{2}{|c|}{ Descriptive Statistics } & \\
\hline Male & N & Minimum & Maximum & Mean & Std. Deviation \\
\hline Female & 23 & 20.00 & 55.00 & 37.1304 & 10.96815 \\
\hline Valid N (listwise) & 7 & 22.00 & 42.00 & 31.8571 & 7.15142 \\
\hline
\end{tabular}

\begin{tabular}{|l|c|c|c|c|}
\hline \multicolumn{5}{|c|}{ Physical Activity } \\
\hline & One-Sample Statistics \\
\hline mild=1, moderate=2, severe=3 & N & Mean & Std. Deviation & Std. Error Mean \\
\hline
\end{tabular}

\begin{tabular}{|l|c|c|c|c|c|c|}
\hline \multicolumn{7}{|c|}{ One-Sample Test } \\
\hline & \multicolumn{7}{|c|}{ Test Value $=0$} \\
\hline & $\mathbf{t}$ & df & $\begin{array}{c}\text { Sig. } \\
\text { (2-tailed) }\end{array}$ & $\begin{array}{c}\text { Mean } \\
\text { Difference }\end{array}$ & $\begin{array}{c}\text { 95\% Confidence Interval of } \\
\text { the Difference }\end{array}$ \\
\hline mild=1, moderate=2,severe=3 & 12.339 & 29 & .000 & 1.40000 & 1.1679 & 1.6321 \\
\hline
\end{tabular}

\begin{tabular}{|l|l|l|l|c|c|}
\hline \multicolumn{7}{|c|}{ Job Strain Index( JSI) } \\
\hline \multicolumn{7}{|c|}{ One-Sample Statistics } \\
\hline $\begin{array}{l}\text { light=1,somewhat hard=2, hard=3, very } \\
\text { hard=4, near maximum=5 }\end{array}$ & N & Mean & Std. Deviation & Std. Error Mean \\
\hline
\end{tabular}

\begin{tabular}{|c|c|c|c|c|c|c|}
\hline \multicolumn{7}{|c|}{ One-Sample Test } \\
\hline & \multicolumn{6}{|c|}{ Test Value $=0$} \\
\hline & \multirow[t]{2}{*}{$\mathbf{t}$} & \multirow[t]{2}{*}{ df } & \multirow{2}{*}{$\begin{array}{c}\text { Sig. } \\
\text { (2-tailed) }\end{array}$} & \multirow{2}{*}{$\begin{array}{c}\text { Mean } \\
\text { Difference }\end{array}$} & \multicolumn{2}{|c|}{$\begin{array}{l}95 \% \text { Confidence Interva } \\
\text { of the Difference }\end{array}$} \\
\hline & & & & & Lower & Upper \\
\hline $\begin{array}{l}\text { light }=1 \text {, somewhat hard }=2 \text {, hard }=3 \text {, } \\
\text { very hard }=4 \text {, near maximum }=5\end{array}$ & 24.083 & 29 & .000 & 3.33333 & 3.0503 & 3.6164 \\
\hline
\end{tabular}

\section{DISCUSSION}

Cardiovascular diseases (CVDs) involve the heart and the blood vessels. There are many risk factors for their development involving unhygienic conditions, poor diet, smoking, lack of physical activities and excessive alcohol intake. ${ }^{1}$ These factors are reflected in patients as hypertension, diabetes, obesity and can lead to heart attack and/or cerebral strokes.

Now-a-days evidence-based medicine and shared decision making have to face many barriers like environmental and systemic issues. ${ }^{12}$
For this, Australia government took timely action and changed their policies to support these areas. ${ }^{13}$ At international levels, especially in UK and US, consultants have been called to change CVDs prevention guideline in light of shared decision making. ${ }^{14}$

Generally, Type 2 diabetes may lead to different vascular complications like hypertension, MI, coronary heart disease and peripheral vascular diseases..$^{15}$ In the present study $10 \%$ of the subjects had diabetes. A study conducted in Korea, the researchers concluded that the 
individuals with the lowest income were more prone to have type II diabetes as compared to the highest income group. ${ }^{16}$

Among males and females, different CVDs prevalence rate was reported. Through clinical studies, a delay of 9 years in the onset of heart attack, in women as compared to males, was found. ${ }^{17}$ The report was strengthened by hospitalized patients' cross-sectional survey for coronary artery disease in which women were found 3.1 years older than men. ${ }^{18}$ Most commonly accepted reason is the protective role of estrogen in females. ${ }^{9}$ While on the other side, lifestyle behavior regarding smoking and alcohol drinking in men, make them more prone to CVDs complications. ${ }^{19}$ In our study, we found that $19 \%$ of office workers were smokers while the smoking prevalence for Pakistani population is $36 \%$ for males and $9 \%$ for females. ${ }^{20}$ In a similar study on young adults in Pakistani university students, smoking prevalence was $23 \%$ with a preponderance of males. ${ }^{21}$ Our study, therefore, highlights that office workers are smoking less than the general population.

Lack of exercise not only causes obesity but also leads to increase in endogenous inflammatory and coagulation factors. Through different reports, we have strong evidence that exercise has a definite role in decreasing the overall risk of CVDs. According to WHO recommendations, regular exercise, healthy diet and no smoking, are the three basic pillars. ${ }^{9}$ In our study work, we found only $20 \%$ workers performed light exercise and exercise frequency was found to be just twice in a week in only $17 \%$ of the workers.

In 2018, Giovanni V22 reported that lifestyle risk factors and work-related conditions are equal clinical risk factors to identify cardiovascular diseases. Although cholesterol smoothens different body functions but when it exceeds its homeostatic levels too much, it becomes a strong risk factor for the development of different CVDs like heart attack, stroke or atherosclerosis. ${ }^{23}$ These patients must have their lipid profile regularly, paying special focus to LDL, TG and HDL. ${ }^{24}$ After conducting a research on rats, Tsukiyama et al, reported vasodilatation and a decrease in lipid profile after a moderate intensity exercise which drops diastolic blood pressure as well. ${ }^{25}$ In our study, $24 \%$ were hypertensive, the same as that in the general Pakistani population. ${ }^{26}$

McPhee et al, reported physical exercise as the best way to prevent and counteract age-related changes in muscle and organic function. ${ }^{27}$ Moreover, slight intensity exercise is better than continuous sitting. It doesn't matter whenever you start, it never too late..$^{28}$

We strongly recommend old office workers, continuously sitting for longer time, the regular consultation regarding their muscular strength and endurance and cardiorespiratory status with graded exercise tests. ${ }^{29}$ The patients with some baseline disease, exercise may trigger the progression of the disease. So tailored exercise may give maximum benefits in normal humans as well as in these patients. ${ }^{30}$

\section{CONCLUSION}

There are strong evidence in support of the role of job strain, lack of exercise and poverty contributing to CHD. It is further strengthened by evidence showing strong relationship between job stress and profound pathological mechanisms. However, the domain still needs more clarification and further research work is needed to determine its specific role in the development and prevention of CHDs.

Copyright@ 27 May, 2020.

\section{REFERENCES}

1. World Health Organization: Cardiovascular diseases (CVDs); 17 May 2017.

2. Yong J, Lin D, Tan XR. Primary prevention of cardiovascular disease in older adults in China. World journal of clinical cases. 2017 Sep 16;5(9):349.

3. Hu CS, Wu QH, Hu DY, Tkebuchava T. Novel strategies halt cardiovascular, diabetes, and cancer strips. Chronic Diseases and Translational Medicine. 2017 Sep 1;3(3):159-64. 
4. Wang $H$, Naghavi M, Allen C, Barber RM, Bhutta ZA, Carter A, Casey DC, Charlson FJ, Chen AZ, Coates $\mathrm{MM}$, Coggeshall M. Global, regional, and national life expectancy, all-cause mortality, and cause-specific mortality for 249 causes of death, 1980-2015: a systematic analysis for the Global Burden of Disease Study 2015. The lancet. 2016 Oct 8;388(10053):1459544.

5. Jiang Y, Mao F, Li Y, Liu J, Zhang Y, Jiang Y, Zhao D, Chen W, Nicholas S, Huo Y, Ge J. Construction of China cardiovascular health index. BMC public health. 2018 Dec 1;18(1):937.

6. Ortega FB, Lavie CJ, Blair SN. Obesity and cardiovascular disease. Circulation research. 2016 May 27;118(11):1752-70.

7. Akil L, Ahmad HA. Relationships between obesity and cardiovascular diseases in four southern states and Colorado. Journal of health care for the poor and underserved. 2011;22(4 Suppl):61.

8. Abdelaal M, le Roux CW, Docherty NG. Morbidity and mortality associated with obesity. Annals of translational medicine. 2017 Apr;5(7).

9. Tian D, Meng J. Exercise for prevention and relief of cardiovascular disease: prognoses, mechanisms, and approaches. Oxidative Medicine and Cellular Longevity. 2019 Apr 1;2019.

10. Hertogh EM, Monninkhof EM, Schouten EG, Peeters $\mathrm{PH}$, Schuit AJ. Validity of the Modified Baecke Questionnaire: comparison with energy expenditure according to the doubly labeled water method. International journal of behavioral nutrition and physical activity. 2008 Dec 1;5(1):30.

11. Hedge Alan, Moore, J.S. Garg, A; Job Strain Index (JSI) DEA4700, (1995) Cornell University, American Industrial Hygiene Journal, 56:443-58, January 2014.

12. Scholl I, LaRussa A, Hahlweg P, Kobrin S, Elwyn G. Organizational-and system-level characteristics that influence implementation of shared decision-making and strategies to address them-a scoping review. Implementation Science. 2018 Dec 1;13(1):40.

13. Trevena L, Shepherd HL, Bonner C, Jansen J, Cust AE, Leask J, Shadbolt N, Del Mar C, McCaffery K, Hoffmann T. Shared decision making in Australia in 2017. Zeitschrift für Evidenz, Fortbildung und Qualität im Gesundheitswesen. 2017 Jun 1;123:17-20.
14. Bonner C, Fajardo MA, Doust J, McCaffery K, Trevena $\mathrm{L}$. Implementing cardiovascular disease prevention guidelines to translate evidence-based medicine and shared decision making into general practice: theory-based intervention development, qualitative piloting and quantitative feasibility. Implementation Science. 2019 Dec 1;14(1):86.

15. Kosiborod M, Gomes MB, Nicolucci A, Pocock S, Rathmann W, Shestakova MV, Watada H, Shimomura I, Chen H, Cid-Ruzafa J, Fenici P. Vascular complications in patients with type 2 diabetes: prevalence and associated factors in 38 countries (the DISCOVER study program). Cardiovascular diabetology. $2018 \mathrm{Dec}$ $1 ; 17(1): 150$.

16. Hwang J, Shon C. Relationship between socioeconomic status and type 2 diabetes: results from Korea National Health and Nutrition Examination Survey (KNHANES) 2010-2012. BMJ open. 2014 Aug $1 ; 4(8)$.

17. O'Neil A, Scovelle AJ, Milner AJ, Kavanagh A. Gender/ sex as a social determinant of cardiovascular risk. Circulation. 2018 Feb 20;137(8):854-64.

18. De Smedt D, De Bacquer D, De Sutter J, Dallongeville J, Gevaert S, De Backer G, Bruthans J, Kotseva K, Reiner Ž, Tokgözoğlu L, Clays E. The gender gap in risk factor control: effects of age and education on the control of cardiovascular risk factors in male and female coronary patients. The EUROASPIRE IV study by the European Society of Cardiology. International journal of cardiology. 2016 Apr 15;209:284-90.

19. Wakabayashi I. Gender differences in cardiovascular risk factors in patients with coronary artery disease and those with type 2 diabetes. Journal of thoracic disease. 2017 May;9(5):E503.

20. Ahmed R, Rizwan-ur-Rashid MP, Ahmed SW. Prevalence of cigarette smoking among young adults in Pakistan. J Pak Med Assoc. 2008 Nov;58(11):597-601.

21. (www.aku.edu/aboutaku/News) accessed on 26 April, 2015.

22. Veronesi $G$, Borchini $R$, Landsbergis $P$, lacoviello $L$, Gianfagna F, Tayoun P, Grassi G, Cesana G, Ferrario MM. Cardiovascular disease prevention at the workplace: assessing the prognostic value of lifestyle risk factors and job-related conditions. International Journal of Public Health. 2018 Jul 1;63(6):723-32.

23. Pereira $\mathrm{H}$. The importance of cholesterol in psychopathology: a review of recent contributions. Indian journal of psychological medicine. 2017 Mar;39(2):109. 
24. Wang $Y, X u$ D. Effects of aerobic exercise on lipids and lipoproteins. Lipids in health and disease. 2017 Dec;16(1):1-8.

25. Tsukiyama Y, Ito T, Nagaoka K, Eguchi E, Ogino K. Effects of exercise training on nitric oxide, blood pressure, and antioxidant enzymes. Journal of Clinical Biochemistry and Nutrition. 2017:16-08.

26. Neupane D, McLachlan CS, Sharma R, Gyawali B, Khanal V, Mishra SR, Christensen B, Kallestrup P. Prevalence of hypertension in member countries of South Asian Association for Regional Cooperation (SAARC): systematic review and meta-analysis. Medicine. 2014 Sep;93(13).
27. McPhee JS, French DP, Jackson D, Nazroo J, Pendleton N, Degens $H$. Physical activity in older age: perspectives for healthy ageing and frailty. Biogerontology. 2016 Jun 1;17(3):567-80.

28. Geneen LJ, Moore RA, Clarke C, Martin D, Colvin LA, Smith $\mathrm{BH}$. Physical activity and exercise for chronic pain in adults: an overview of Cochrane Reviews. Cochrane Database of Systematic Reviews. 2017(4).

29. Sullivan AN, Lachman ME. Behavior change with fitness technology in sedentary adults: a review of the evidence for increasing physical activity. Frontiers in public health. 2017 Jan 11;4:289.

30. Jones LW, Eves ND, Scott JM. Bench-to-bedside approaches for personalized exercise therapy in cancer. American Society of Clinical Oncology Educational Book. 2017 Jan 1;37:684-94.

\begin{tabular}{|c|c|c|c|}
\hline \multicolumn{4}{|c|}{ AUTHORSHIP AND CONTRIBUTION DECLARATION } \\
\hline Sr. \# & Author(s) Full Name & Contribution to the paper & Author(s) Signature \\
\hline 1 & Qamar Mehboob & Data analysis. & \\
\hline 2 & Waqar Arif & Data collection. & work \\
\hline 3 & Sana Arif & Data collection. & \\
\hline
\end{tabular}

